\title{
Documenting patient risk and nursing interventions: record audit
}

\section{AUTHORS}

KASIA BAIL RN, BN(Hons), GCHE, PhD ${ }^{1}$

EAMON MERRICK RN, BH(Nursing), GCES, MHlthServMgmt, PhD ${ }^{2}$

CHRYSTA BRIDGE RN, BN, GCIN, BMS 3

BERNICE REDLEY RN, BN(Hons), Crit Care Cert, $\mathrm{PhD}^{4}$
1 University of Canberra, ACT, Australia

2 Nursing, Auckland University of Technology, Auckland, New Zealand

3 Membership Services, Australian College of Nursing, ACT, Australia

4 Centre for Quality and Patient Safety Research-Monash Health Partnership, Deakin University, Victoria, Australia

\section{CORRESPONDING AUTHOR}

BERNICE REDLEY Centre for Quality and Patient Safety Research-Monash Health Partnership, Deakin University Burwood, 221 Burwood Highway, Burwood. Victoria, Australia. Phone: +61 392446807.

Email: bernice.redley@deakin.edu.au

\section{ABSTRACT}

Objective: The aim was to explore and compare documentation of the nursing process for patient safety in two nursing documentation systems: paper and digital records.

Background: The 'nursing process' (assessment, planning, intervention, and evaluation) is recommended by professional nursing registration and health service accreditation bodies as a key component of understanding nurses' clinical reasoning. Nurses' responsibility for patient safety must be supported by comprehensive documentation practices.

Study design and methods: A retrospective audit of twenty clinical care records $(\mathrm{N}=20)$ randomly selected from a single acute medical ward at a tertiary hospital in Australia; ten from a digital trial that replicated selected paper forms and ten paper records as controls. The audit was conducted by two nurse researchers using a purpose built data extraction tool.

Results: Patient age, gender and primary diagnoses were similar for the digital and paper care records. Documentation of the full nursing process was low in both record types, and comprehensiveness of nursing documentation was similar across the paper and digital records. Compared to the paper documents, the digital documents were more often rated as 'complete' $(p<0.05)$. Documentation of risk to skin integrity $(p<0.05)$ and evidence of completed nursing interventions to address risks were more frequent $(p<0.05)$ in digital records.

Discussion: The findings of this study highlight an important gap in comprehensive documentation of the nursing process that supports and informs the clinical reasoning of nurses for patient safety. Improvements in digital documents reflect future opportunity to enhance the quality of nurse documentation using technology specific strategies such as prompts, visualisation and nudge.

Conclusion: This research identifies that both paper and digital systems of hospital documentation may fail to capture and communicate the clinical reasoning of nurses. Digital systems have the potential to improve capture of the clinical reasoning and nursing process.

What is already known about the topic?

- Professional registration and healthcare accreditation bodies recommend nurses' clinical decision making is underpinned by processes of assessment, planning, intervention and evaluation.

- Poor capture of nurses' clinical decision making in their documentation has negative consequences for the continuity, quality and safety of care; including inadequate detection of deterioration and escalation of care. 
- Electronic systems are expected to enhance capture of nurse decision making in documentation.

What this paper adds:

- Nurses' clinical reasoning was poorly captured in both paper and digital documentation systems.

- Nurses documented their intervention responses to identified patient risks more often in the digital system compared to paper records.
- Digital systems offer an opportunity to proactively nudge nurses towards improved documentation of nursing processes.

Key words: Nursing administration; nursing; nursing informatics; documentation in the organisation of care; behavioural economics

\section{OBJECTIVE}

The implementation of digital nurse documentation systems into hospitals provides opportunities to optimise and fundamentally redesign communication about nurses' clinical reasoning processes, integrate data, and create smarter workflows. A common goal is to enhance the quality and relevance of nurse documentation of care delivery to meet National Safety and Quality Health Service Standards while simultaneously enhancing care quality and reducing the amount time nurses spend on activities that do not add value and administrative compliance. ${ }^{1}$ There is a need for the design and implementation of digital systems be informed by nursing theory and a strong understanding of the nursing process in order to fit nursing workflows. To achieve this, it is important to explore if and how the transfer of nursing forms to digital health information systems can accurately capture the clinical reasoning of nurses and reflect nursing work. The objective of this study was therefore to describe the documentation of the nursing process in terms of quality and completeness using paper and digital nurse documentation systems in an acute medical ward in Australia.

\section{BACKGROUND}

Within the acute hospital care sector nurses are the professional group who most frequently document patient risk screening, assessment and care delivery. Previous research suggests nursing documentation has frequent gaps or inconsistencies, and can be difficult to locate and interpret, thereby contributing to patient safety errors or harm. ${ }^{2}$ There is little evidence to suggest digital nor paper health records adequately support the documentation needs of the nursing profession, and this is a common and international problem. ${ }^{3}$ Failure to capture the clinical reasoning of nurses in their documentation creates flow-on effects for the continuity, quality, and safety of care. ${ }^{4}$ For example, it has been demonstrated that poor quality nurse care plans create opportunities for errors of both omission and commission. ${ }^{5}$ Further, gaps in documentation of patient vital signs can lead to inadequate detection of deterioration and escalation of care. ${ }^{6}$ Little is known about how 'fit for purpose' digital nursing records are as the usability of digital documentation systems can be conflated with user satisfaction. ${ }^{7}$ This poses a challenge for the developers of digital documentation systems and suggests that specific measures of 'fit for purpose' should be used. There are also contextual challenges associated with the development and deployment of systems to support effective nurse documentation in different care settings. For example, digital system developers may attempt to accommodate the clinical needs of nurses, but encounter administrative, institutional or policy barriers. These barriers can result in the replication of problems experienced with the existing, often inadequate, paper-based records. ${ }^{8,9}$

The nursing profession is guided by processes of clinical reasoning used to make decisions in practice which are consistent with patient choice and current best evidence about healthcare. ${ }^{10}$ 'Clinical reasoning' and 'clinical decision making' are underpinned by a cycle of 'assessment, diagnosis, planning, intervention and evaluation', referred to as the 'nursing process'. ${ }^{11}$ This decision-making framework is used by nurses in daily practice, and often cited in key registration competencies and hospital accreditation requirements. ${ }^{12,13}$ Structured capture and communication of the clinical reasoning of nurses through the nursing process has been used to link nursing work to reduced hospital length of stay, reduced mortality and improved quality of life for hospitalised patients. ${ }^{4,15}$ Hadij suggested that when digital records were adapted to capture nursing data and terminology, nurses' acceptance of the system improved $(\geq 25 \%) .{ }^{16}$ In contrast, a system unable to capture and communicate nursing processes can force nurses to create 'workarounds' which involve documentation outside of the formal system. ${ }^{17,18}$ These workarounds reflect a failure of the documentation system to accurately reflect the nursing process and support nurses' work. In addition to service and care inefficiencies the authors argue that such workarounds prevent organisational learning about nursing work, 19,20 the long-term consequences of which are negative impacts on the quality and safety of patient care. ${ }^{21}$ Bail et al. argued that workarounds are more likely to occur when the original co-designed system is subverted to meet the needs of the institution rather than the clinician. ${ }^{18}$ For these reasons it is 
important to explore if digital health information systems accurately reflect and capture the clinical reasoning of nurses prior to their implementation.

\section{METHODS}

The study was a retrospective cohort study using audit of nursing documentation recorded in patient medical records during and after the trial of a novel digital nurse documentation system. The setting was a single acute medical ward of a tertiary hospital located in a capital city in Australia. Approximately $85 \%$ of the nurses working on the ward were registered nurses, with a small proportion of enrolled nurses.

\section{PARTICIPANTS}

Twenty patient care records were randomly sampled at two time points: (1) during the trial of a digital nursing documentation system (10 records between March and April 2017); and (2) records from the following year after completion of the trial, when use of usual paper records had resumed (10 records in April 2018). The 20 patient records audited were selected using a random number generator applied to Time 1 during the trial of electronic documents (10 records) and Time 2 at the same time in the following year to avoid potential bias related to seasonal variation and allow sufficient time for washout of any ongoing effect of the digital system. This sample size was consistent with a previous study examining nursing documentation, ${ }^{22}$ and was expected to provide enough data for a rich representation of the complexity of nursing documentation while ensuring manageability of data collection and accuracy of analysis.

\section{INTERVENTION}

The Australian-based technology piloted in this project was designed with the specific goal of supporting quality and safe nursing practice, reducing administrative burdens of nursing documentation and thereby releasing time for better nursing care. The technology had previously been through several cycles of iterative design testing in a laboratory, using simulation and in different 'real world' clinical settings. ${ }^{18,23-27}$ The health information technology platform was accessed by point-of-care large touch screen devices with adjustable arms affixed to the wall at each patient bedside, based on preferences made by nurses in previous studies. Prior to implementation, the health information system provider engaged with internal stakeholders including representatives of the hospital executive, Clinical Nurse Consultants (CNCs) (regarded as experts in the clinical specialty), senior nursing staff in the organisation, and a nursing information technology system expert about design of the system. These stakeholders convened a steering group, a clinical working group, and a technical working group that informed the scope and range of nursing documentation that would be migrated from the existing paper-based system to the digital system, as well as the implementation strategy and response to emerging challenges. Key decisions made by these groups included: installation on a 26-bed medical ward; eight nurses trained as 'super-users' to support other staff and test the technology; a four week pilot duration; selection of 11 (out of 55) commonly used paper forms related to core nursing care activities to be converted into electronic format for use in the system; use of a hybrid 'paper-lite' documentation process whereby existing paper files were used for medication administration, record writing and any nursing assessments outside of the 11 selected digitised forms. The 11 selected forms were only available on the electronic system for the duration of the study, and it was specified that for system-wide continuity the electronic forms replicated the appearance of pre-existing paper documents.

\section{ETHICS}

This study was approved by a Hospital and University Human Research Ethics Committee (reference number ETH.6.16.112).

\section{DATA COLLECTION PROCEDURE}

Data were extracted by two researchers, one an academic nurse researcher and the other an experienced clinical nurse. Demographic data were collected from the patient hospital label and discharge summary. To provide homogeneity, only nursing notes recorded up to 48 hours following the first recorded nursing entry (i.e. admission) were reviewed for data extraction. The full patient record was examined for documentation of nursing activities including observation charts, clinical progress notes, nursing care plans, the patient care and accountability plan and the patient journal. All nursing documentation (paper and/or digital) that provided enough information for the rater to understand the care provided were used for data extraction; illegible or unclear entries were excluded.

\section{MEASURES}

The items in the purpose developed data extraction tool (Table 1) were derived from tools previously used to examine documentation of the nursing process and the nursing management of factors contributing to common preventable harms. ${ }^{22,28-31}$ Quality and completeness of documentation of the nursing process were defined by (1) the comprehensiveness of documentation to capture all four steps of the nursing process; (2) individualisation of care through the comprehensive documentation of patient risk assessment, planning, interventions and evaluation performed by nurses, and the inclusion of components expected for delivering holistic patient care such as the patient's social situation, coping, beliefs, information from significant others or hobbies. The items extracted from the clinical record are presented in Table 1. 
TABLE 1: EXTRACTION ITEMS FOR CLINICAL AUDIT OF DOCUMENTATION FOR NURSING PROCESS

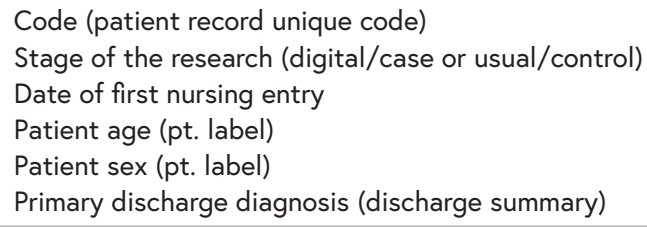

1.11 Relevant nursing priorities

1.12 Field notes

1.12 Each entry is clearly authored

1.13 The documentation is legible (includes only approved abbreviations)

1.15 All nursing statements provide sufficient information for the reader to be sure about the care provided

Code of risk identified in assessment

Brief description of risk

Location of nurse identification of risk

\section{Planning}

2.1 Nursing problem is documented

2.2. Aetiology/contributing factors are documented (primary causes)

2.3 Signs and symptoms are documented

2.4 Contributing factors and symptoms are consistent correctly interpreted

2.5 A nursing goal corresponds to the nursing problem

2.6 A nursing plan to meet the goal is documented

3. Interventions

3.1 Count of nursing interventions named

3.2. Count of nursing intervention documented as completed

3.3 Name the nursing interventions

\section{Outcomes}

4.1 Update of care plan each day/or when change identified

4.2 The nursing outcome describes if there is a change in patient symptoms/risk

4.2 Nursing outcome is documented for the risk

4.3 There is a relationship between the nursing problem, intervention and outcome

^MEWS - Modified Early Warning Scale, used in conjunction with the observation and measurement of vital signs to trigger escalation of clinical and medical support in relation to patient deterioration. ${ }^{\wedge \wedge} \mathrm{A}-\mathrm{PINCH}$ (a group of medicines that should universally be considered as high-risk. These medicines include anti-infective agents, anti-Psychotics, Potassium, Insulin, Narcotics and sedative agents, Chemotherapy and Heparin and other anticoagulants).
All data extracted for the audit were relevant to nursing care on an acute medical inpatient ward, expected to be evident in both written and digital forms, and relevant to nurses' roles in risk management and harm prevention. The extracted items (Table 1) were collated into two groups: (1) 'Assessment' included the information gathered on patient admission and identification of individual risks; and (2) 'Planning and Nurse Intervention' included naming the nursing problems addressed during the admission, interventions identified in the nursing care plan, interventions documented as being delivered, and documented evaluation of patient outcomes within the selected timeframe. For the purpose of this study, measures were calculated to examine:

(1) Comprehensiveness: scored by rating each element of the nursing care plan as $0=$ not documented; $1=$ partially documented (incomplete) and $2=$ comprehensively documented. Sum scores were calculated for each group using the ratings for all the 'Assessment' $(\mathrm{n}=2 \mathrm{O})$ and 'Planning and nurse interventions' $(\mathrm{n}=57)$ items extracted from the nursing documentation, with possible scores between $0-40$ and $0-24$ respectively.

(2) Individualisation: measured using a count of the number of documented patient safety risk assessments, the number of interventions performed by nurses to address each identified risk, and a count of the number of elements included in the holistic patient care content in relation to $1-9$ in 1) 'Assessment'.

\section{DATA QUALITY}

Prior to data extraction, data reliability was enhanced by two independent researchers using the data extraction tool to examine the same records until acceptable (100\%) interrater agreement was established. In addition, decision rules were created (Table 2) and used to ensure consistency of extraction. For example, only nursing notes documented during the first 48 hours of each patient record were examined to mitigate potential for bias associated with the variable length of stay. While this timeframe provided consistency in nurse documentation, it limited opportunity for data capture of nurse documentation about evaluation of intervention impact and patient outcomes. Transparency of data capture was supported by field notes kept by the data extractors to provide an audit trail and ensure consistency during data extraction and analysis. Content validity of the data extraction tools was derived from previous validation reported in the literature, ${ }^{22,28-31}$ and face validity from review by three expert members of the research team. 


\section{TABLE 2: RULES FOR DATA EXTRACTION}

Review the first 48 hours from the first recorded nursing entry

The assessment component is completed once for each patient

Demographic data was collected for each patient from patient label and discharge summary

Use only documents used for evaluation of the nursing process are:

- Patient care and accountability plan (paper or digital);

- Patient journal, nurse activities (digital);

- Patient progress notes (paper);

- Only authorised abbreviations for the facility are used.

All nursing statements provide sufficient information for the reader to be sure about the care provided.

The planning intervention is completed for each risk/deficit identified (this may result in more than one care plan evaluated for each patient)

\section{DATA ANALYSIS}

All data were collated, coded, and imported into SPSS Version $24^{\mathrm{TM}}$ for analysis. Frequencies and distributions were examined using descriptive statistics. Continuous variables were analysed using independent samples t-tests, and categorical or non-normal variables were analysed using nonparametric tests including Chi-square and Mann Whitney-U test to examine for differences in documentation between the digital and paper nursing documents.

\section{RESULTS}

The characteristics of the patient subjects (see Table 2) were similar in age (digital $\mathrm{M}=62.4, \mathrm{SD}=16.3$ vs paper $\mathrm{M}=64$, $\mathrm{SD}=21.5, p>0.05$ ) and gender (digital $30 \%$ male vs paper $60 \%$ male, $p>0.05$ ) across the two groups. The primary discharge diagnosis was varied in both groups, as expected for a medical ward. From the 20 records, 57 nurse care plans specific to the needs identified by nurses for each patient (digital $29 \mathrm{vs}$ paper 30) were available for analysis (Table 3).

Examination of the distributions of "comprehensiveness scores' calculated from the extracted audit data for overall nurse documentation revealed low mean scores (Table 4) indicating overall poor documentation of the nursing process in both groups.

Comparison of nurse documentation comprehensiveness scores for the digital and paper documents using independent samples t-test revealed no significant difference in nurse documentation of Assessment, (digital, $\mathrm{M}=11, \mathrm{SD} 3.8$ vs paper $\mathrm{M}=9$, SD2.3; $\mathrm{t}(18)=1.59 ; \mathrm{p}=.13$ ) or Planning and nurse intervention (digital $\mathrm{M}=11, \mathrm{SD} 3.8$ vs paper $\mathrm{M}=9$, SD2.3; $\mathrm{t}(57)=.1419 ; \mathrm{p}=.89$ ). However, further visual examination of patterns in the data revealed trends in the comprehensiveness score data suggesting higher scores for all assessment items in the digital system when compared to the paper documents.

TABLE 3: DEMOGRAPHICS OF 'DIGITAL/CASE' AND 'PAPER/CONTROL' SAMPLES

\begin{tabular}{|c|c|c|c|c|c|}
\hline Code & $\begin{array}{l}\text { Stage of the research } \\
\text { (Digital or Paper) }\end{array}$ & $\begin{array}{l}\text { Age } \\
\text { (yrs) }\end{array}$ & Sex & Primary discharge diagnosis (discharge summary) & $\begin{array}{l}\text { Care plans } \\
\text { evaluated }\end{array}$ \\
\hline 1 & Digital & 51 & M & Left pleural effusion & 1 \\
\hline 2 & Digital & 67 & M & For lymph node biopsy & 2 \\
\hline 3 & Digital & 67 & $\mathrm{~F}$ & Urinary Tract Infection & 2 \\
\hline 4 & Digital & 87 & $\mathrm{~F}$ & Infective endocarditis & 1 \\
\hline 5 & Digital & 55 & $\mathrm{~F}$ & Right upper lobe cavitating pneumonia & 1 \\
\hline 6 & Digital & 66 & M & Metastatic oesophageal cancer & 6 \\
\hline 7 & Digital & 29 & $\mathrm{~F}$ & Viral Upper Respiratory Infection & 3 \\
\hline 8 & Digital & 72 & $\mathrm{~F}$ & Abdominal pain and fever related to Peritoneal Dialysis infection & 4 \\
\hline 9 & Digital & 52 & $\mathrm{~F}$ & Wound ooze post Total Knee Replacement & 4 \\
\hline 10 & Digital & 78 & $\mathrm{~F}$ & Confusion and headaches & 4 \\
\hline 11 & Paper & 89 & M & Pneumonia & 4 \\
\hline 12 & Paper & 34 & $\mathrm{~F}$ & Syncope for Investigation & 2 \\
\hline 13 & Paper & 78 & M & Abdominal pain for Investigation & 2 \\
\hline 14 & Paper & 72 & $\mathrm{~F}$ & Multi trauma transfer from Japan & 1 \\
\hline 15 & Paper & 20 & $\mathrm{~F}$ & Infective exacerbation Cystic Fibrosis & 2 \\
\hline 16 & Paper & 68 & M & Urinary Tract Infection & 3 \\
\hline 17 & Paper & 70 & $\mathrm{~F}$ & Delirium background Korsakoff's dementia & 3 \\
\hline 18 & Paper & 76 & M & Recurrent malignant pleural effusion & 5 \\
\hline 19 & Paper & 56 & M & Percutaneous Endoscopic Gastrostomy insertion & 5 \\
\hline 20 & Paper & 77 & M & Gastrointestinal bleed & 3 \\
\hline
\end{tabular}


TABLE 4: DISTRIBUTIONS OF SCORES FOR COMPREHENSIVE NURSE DOCUMENTATION

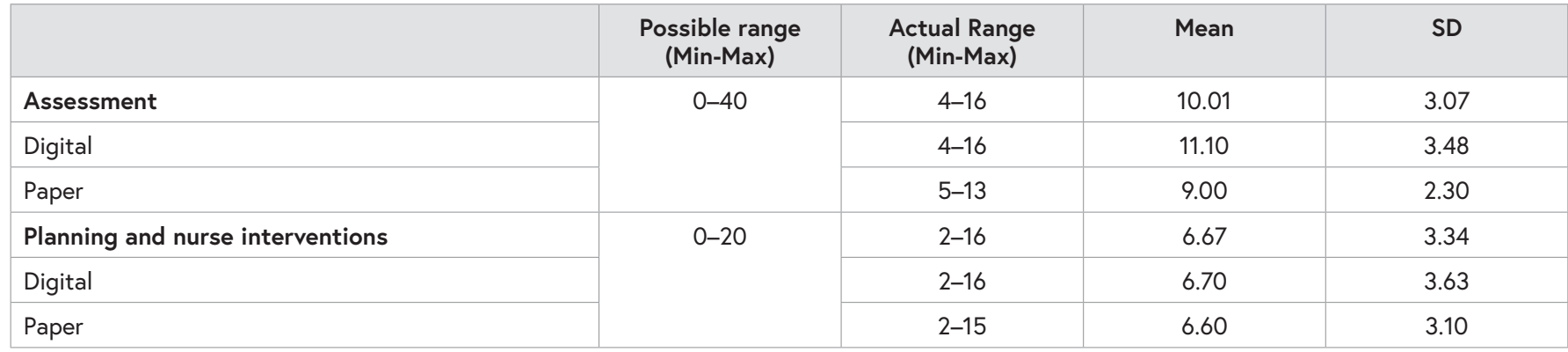

Examination of scores for individual assessment items revealed the digital records more often included detail of risk assessment $(p=0.01)$; specifically, assessment of skin integrity $(p=0.06)$, medication risk $(p=0.09)$, and the situation leading to hospitalisation $(p=0.01)$ were documented more often in digital compared to paper documents. Components of 'holistic care' such as anxiety, social situation, coping, beliefs, information from significant others or hobbies were not included in either record type, despite these being data collection items included on both forms.

Analysis of trends in the nurse documentation of Planning and nurse intervention items similarly suggested comprehensive nurse documentation more frequently occurred in the digital documents compared to paper documents, but these differences were non-significant. While the average number of nursing interventions named in the digital care plans $(M=3.17, S D=3.89)$ was similar to the paper documents $(M=2.2, S D=2.08), t(42.5)=1.19 ; \mathrm{p}=0.24$, there was a significant difference in the number of nursing interventions documented as completed in the digital $\left(M=3.14, S D_{3.9}\right)$ compared to paper documents $(M=1.2, S D 1.2), t(33 \cdot 3)=2.589$; $\mathrm{p}=.01$ (Table 5 ).

\section{DISCUSSION}

The findings of this study highlight an important gap in comprehensive documentation of the nursing process that supports and informs the clinical reasoning of nurses. In this study, similar to previous studies, consistent gaps in documentation of the nursing process were evident in both paper and digital nursing documentation. ${ }^{2}$ Overall, the documentation of assessment and interventions was more comprehensive than planning and evaluation. There was some indication that the overall documentation of the nursing process was better in the digital documents compared to the paper documents, but this improvement was not significant.

Specific aspects of nursing care, such as completed interventions and assessment of risk, were more frequently documented in the digital record. It is possible that this was due to the processes for how care was documented, for example, digital records were contemporaneous whereas paper documentation was usually completed at the end of
TABLE 5: FREQUENCY OF COMPREHENSIVE NURSE DOCUMENTATION OF PLANNING, INTERVENTIONS AND OUTCOME

\begin{tabular}{|c|c|c|c|}
\hline & $\begin{array}{l}\text { Digital } \\
(n=29)\end{array}$ & $\begin{array}{l}\text { Paper } \\
(n=30)\end{array}$ & $\mathbf{p}$ \\
\hline \multicolumn{4}{|l|}{ 2. Planning } \\
\hline 2.1 Nursing problem is documented & 5 & 0 & 0.17 \\
\hline $\begin{array}{l}\text { 2.2. Aetiology/contributing factors } \\
\text { are documented (primary causes) }\end{array}$ & 4 & 1 & 0.15 \\
\hline $\begin{array}{l}\text { 2.3 Signs and symptoms are } \\
\text { documented }\end{array}$ & 5 & 3 & 0.42 \\
\hline $\begin{array}{l}2.4 \text { Contributing factors and } \\
\text { symptoms are consistent- correctly } \\
\text { interpreted }\end{array}$ & 1 & 7 & 0.31 \\
\hline $\begin{array}{l}2.5 \text { A nursing goal corresponds to } \\
\text { the nursing problem }\end{array}$ & 0 & 0 & \\
\hline $\begin{array}{l}2.6 \text { A nursing plan to meet the goal } \\
\text { is documented }\end{array}$ & 1 & 0 & .31 \\
\hline \multicolumn{4}{|l|}{ 3. Interventions } \\
\hline $\begin{array}{l}\text { 3.1 Count of nursing interventions } \\
\text { named }\end{array}$ & $\begin{array}{c}3.17 \\
(3.89)\end{array}$ & $\begin{array}{l}2.2 \\
(2.01)\end{array}$ & .23 \\
\hline $\begin{array}{l}\text { 3.2. Count of nursing intervention } \\
\text { documented as completed }\end{array}$ & $\begin{array}{l}3.14 \\
(3.9)\end{array}$ & $1.2(1.2)$ & $0.01^{*}$ \\
\hline \multicolumn{4}{|l|}{ 4. Outcomes } \\
\hline $\begin{array}{l}\text { 4.1 Update of care plan each day/or } \\
\text { when change identified }\end{array}$ & 0 & 0 & \\
\hline $\begin{array}{l}4.2 \text { The nursing outcome describes } \\
\text { if there is a change in patient } \\
\text { symptoms/risk }\end{array}$ & 3 & 1 & 0.28 \\
\hline $\begin{array}{l}4.2 \text { Nursing outcome is documented } \\
\text { for the risk }\end{array}$ & 5 & 2 & 0.21 \\
\hline $\begin{array}{l}4.3 \text { There is a relationship between } \\
\text { the nursing problem, intervention } \\
\text { and outcome }\end{array}$ & 3 & 1 & 0.29 \\
\hline
\end{tabular}

a shift when care would be summarised such as "pressure area care was attended". Therefore, the frequency of such an intervention over the course of a shift was often not evident in the paper record. This finding highlights some common pitfalls in traditional nurse workflows that can be mitigated by new workflows associated with implementation of digital records such as avoiding the replication of data often evident across multiple paper forms, ${ }^{18}$ and replacing the practice 
of retrospectively documenting patient care at the end of a shift with contemporaneous recordkeeping. Traditional practices that encouraged the use of global statements about the interventions provided during a shift in an end-of-shift report, meant the researchers were unable to extract detail about the nursing process.

Omissions of patient-specific information, such as psychosocial assessment and the patient's experience of care were observed in this study, in both the digital and paper formats, are of concern. High-quality care is dependent on individualised care, ${ }^{32}$ particularly for complex medical patients with multiple care needs. ${ }^{33}$ Digital systems provide the opportunity to respond to the needs of this population by capturing the complexity of the nursing work needed to respond to changing risk profiles and specific needs of each hospitalised patient. ${ }^{22,33}$ Healthcare organisations, registration boards and accreditation bodies emphasise the delivery of person-centred care. ${ }^{12-13}$ However, this research highlights that work processes and systems of documentation may reinforce failures to comprehensively document nursing processes. The implementation of digital systems should be viewed as an opportunity to address multiple failures in both nurse workflows and paper records, by proactively nudging towards desired behaviours. ${ }^{32,37-38}$

'Nudges' commonly used in healthcare practices include the order of information gathering by prompting some options that are presented visually first or using a common option to accept as a default. ${ }^{35,36}$ Emerging “Nudge Units" have been shown to aid health services by the intentional structuring of choice presentations to increase the frequency of evidence-informed choices. 35,36,39 Increasingly, work is occurring with nursing practice to recognise and consciously develop nudge tactics that are most effective. ${ }^{37}$ For example, Ostrovsky implemented a program to guide nurses through a systematic patient review and physical exam, ${ }^{40}$ a falls risk protocol, and other assessments with software-based behavioural "nudges" used to suggest most appropriate (evidence-informed) and immediate nursing interventions to minimise errors and improve speed of data entry. Their findings confirmed that nurse participants found the nudge system improved their likelihood of identifying patient complications, lowered error rates by encouraging realtime documentation, and the system was found to improve nurse documentation comprehensiveness and clarity. $4^{\circ}$ Our findings revealed similar trends that suggest using nudges such as automatic care plan suggestions may be effective to improve nurse documentation; however, the small sample makes it difficult to draw conclusive comments. There is a need to determine if and how different nudges, including those embedded in the structures of paper or electronic health records can be used to improve nurses' documentation of clinical care..$^{41}$
Conversely, concerns that 'nudging' practice may reinforce passive 'task orientated' documentation are evident in the literature ${ }^{32}$ particularly if electronic documentation mimics the high burden of paper documentation. Ensuring digital systems enable individualisation tailored to patient needs is key. ${ }^{4^{\circ}}$ Careful electronic system development can effectively draw on nurses' judgement and use nudges to guide effective decision-making process (assessment, diagnosis, planning, intervention and evaluation) that is evidence-informed and specific to patient needs. For these reasons it is critical to develop a comprehensive body of evidence about the relationship between nurse documentation, the realities of clinical work, and desirable clinical behaviours.

\section{LIMITATIONS}

Strategies used to minimise the risk for potentially confounding factors to impact the study data included data extraction from patients admitted to the same ward to minimise influence of different ward culture, staff and patient type; also, records from the same time of year were used to minimise possible seasonal influences. Limitations of this study relate to the small sample size, the specific context in which it was undertaken, and the considerable amount of missing data in both paper and digital patient records; a well acknowledged common problem impacting previous examinations of nursing documentation. ${ }^{2}$ In this study that evaluated the documentation available in care records, some paper and digital documents could not be located for audit, hence were assumed to be lost or misplaced. Unfamiliarity and implementation challenges related to introduction and testing of the digital system may have impacted the quality of nurse documentation in the digital records during the pilot. Most notably, some operational decisions meant that the majority (6/8) of trained super users were redeployed to other wards; there was a $31 \%$ increase in the number of patients admitted to the ward during the technology pilot period; and average patient length of stay decreased by four days during that period. ${ }^{18}$

\section{CONCLUSION}

This study found poor documentation of the nursing process for clinical reasoning in both paper and digital systems. The study highlights that replication of paper forms into digital platforms may not be ideal as it can perpetuate poor workflows, gaps and duplication, and can exacerbate preexisting problems. We identified that some elements of nurse documentation were better in the digital system, most notably the completion of nursing interventions in response to the assessment of risk. This finding suggests digital systems offer promise, but further research is needed to ensure that nursing theory underpins design of digital health systems for nursing documentation to be 'fit for purpose'. 


\section{IMPLICATIONS FOR RESEARCH, POLICY, AND PRACTICE}

Nurses are expected to provide comprehensive records of patient care in hospitals. It is critical that nursing documentation captures the clinical reasoning of nurses to support effective nursing workflows. This study reveals that the nursing process, that underpins nurses' clinical reasoning, is poorly captured in current documentation systems.

Implementation of digital records provides an opportunity to achieve goals of comprehensive documentation; however, the findings of this study suggest more work is needed to optimise the transfer of nurse documentation to electronic nursing documentation. Strategies to fill gaps related to the application and evidence of nursing theory in electronic nursing documentation may include adoption of a nationally accepted standardised nursing language; consistent teaching and use of the nursing process in clinical practice; and nurse involvement at all stages of digital system design. Future development to transition and optimise nursing documentation in electronic systems should be informed by nursing theory to address these gaps.

\section{ACKNOWLEDGEMENTS}

We acknowledge the support of the 'Synergy Nursing and Midwifery Research Centre' of ACT Health and University of Canberra for in-kind support and Tracy Douglas for assisting with preparation and editing of this manuscript.

\section{FUNDING SUPPORT}

This project was an extension of a project funded by an Innovations Connections Project grant ( $\left.\mathrm{RC}_{51279}\right)$ from the Commonwealth Department of Industry, Innovation and Science and their industry Project Partner Humanetix.

\section{CONFLICTS OF INTEREST}

As part of the funding agreement, the joint funders were able to review manuscript content prior to submission but were unable to withhold consent for publication or demand any changes.

\section{REFERENCES}

1 Australian Commission on Safety and Quality in Health Care (ACSQHC). National safety and quality health service standards: second edition. Australian Commission on Safety and Quality in Health Care. Sydney, NSW. 2017. [cited 2021 Jan 20] Available from: https://www.safetyandquality.gov.au/ publications-and-resources/resource-library/national-safetyand-quality-health-service-standards-second-edition

2 Charalambous L, Goldberg S. 'Gaps, mishaps and overlaps' Nursing documentation: how does it affect care? J Res Nurs. 2016; 21(8), 638-48. Available from: https://doi. org/10.1177/1744987116678900.
3 Topaz M, Ronquillo C, Peltonen LM, Pruinelli L, Sarmiento RF, Badger MK, et al. Nurse informaticians report low satisfaction and multi-level concerns with electronic health records: results from an international survey. AMIA Annu Symp Proc. 2016; 2016(2016-2025).

4 Clancy L, Happell B. Being accountable or filling in forms: managers and clinicians' views about communicating risk. Perspect Psychiatr Care. 2017; 53(1): 38-46. Available from: https://doi.org/10.1111/ppc.12135.

5 Cho E, Lee NJ, Kim EY, Kim S, Lee K, Park KO, et al. Nurse staffing level and overtime associated with patient safety, quality of care, and care left undone in hospitals: a crosssectional study. Int J Nurs Stud. 2016; 60: 263-71. Available from: https://doi.org/10.1016/j.ijnurstu.2016.05.009.

6 Considine J, Trotter C, Currey J. Nurses' documentation of physiological observations in three acute care settings. $J$ Clin Nurs. 2016; 25(1-2), 134-43. Available from: https://doi. org/10.1111/jocn.13010

7 Kovinen T, Lammintakanen J. The success of a management information system in health care - a case study from Finland. Int J Med Inform. 2013; 82(2), 90-7. Available from: https://doi. org/10.1016/j.ijmedinf.2012.05.00.

8 Bruylands M, Paans W, Hediger H, Muller-Staub M. Effects on the quality of the nursing care process through an educational program and the use of electronic nursing documentation. Int J Nurs Know. 2013; 24(3), 163-70. Available from: https://doi. org/10.1111/j.2047-3095.2013.01248.x.

9 Wang N, Hailey D, Yu P. Quality of nursing documentation and approaches to its evaluation: a mixed-method systematic review. J Adv Nurs. 2011; 67(9), 1858-75. Available from: https://doi.org/10.1111/j.1365-2648.2011.05634.x.

10 Levett-Jones T, Hoffman K, Dempsey J, Jeong SYS, Noble $D$, Norton CA, et al. The 'five rights' of clinical reasoning: an educational model to enhance nursing students' ability to identify and manage clinically 'at risk' patients. Nurse Educ Today. 2010; 30(6): 515-20. Available from: https://doi org/10.1016/j.nedt.2009.10.020

11 Cashin A, Heartfield M, Bryce J, Devey L, Buckley T, Cox D, et al. Standards for practice for registered nurses in Australia. Collegian. 2017; 24(3): 255-66. Available from: https://doi. org/10.1016/j.colegn.2016.03.002

12 Australian Commission on Safety and Quality in Health Care (ACSQHC). Australian safety and quality framework for health care: putting the framework into action: getting started. 2011. [cited 2020 Feb 1] Available from: https:// www.safetyandquality.gov.au/wp-content/uploads/2011/01/ ASQFHC-Guide-Healthcare-team.pdf.

13 Nursing and Midwifery Board of Australia (NMBA). Registered nurse standards of practice. 2016. [cited 2020 Feb 1] Available from: https://www.nursingmidwiferyboard.gov.au/codesguidelines-statements/professional-standards/registerednurse-standards-for-practice.aspx

14 Paans W, Muller-Staub, M, Krijnen WP. Outcome calculations based on nursing documentation in the first generation of electronic health records in the Netherlands. Stud Health Technol Inform. 2016; 225: 457-60. Available from: https://doi, org/10.1111/j.1365-2648.2010.05302.x.

15 Sanson G, Vellone E, Kangasniemi M, Alvaro R, D'Agostino F. Impact of nursing diagnoses on patient and organisational outcomes: a systematic literature review. J Clin Nurs, 2017; 26(23-24): 3764-83. Available from: https://doi.org/10.1111/ jocn.13717. 
16 Hadji B, Martin G, Dupuis I, Campoy E, Degoulet P. 14 years longitudinal evaluation of clinical information systems acceptance: the HEGP case. Int J Med Inform. 2016; 86: 20-9. Available from: https://doi.org/10.1016/j.ijmedinf.2015.11.016.

17 Boonen M, Rankin J, Vosman F, Niemeijer AJH. Nurses' knowledge and deliberations crucial to Barcoded Medication Administration technology in a Dutch hospital: discovering nurses' agency inside ruling. Health. 2018; 1363459318800155 Available from: https://doi.org/10.1177/1363459318800155.

18 Bail K, Merrick E, Redley B, Gibson J, Davey R, Currie M. "Blind leading the blind": qualitative evaluation of unanticipated difficulties during nurse testing of a hospital health information system. Collegian. 2019; 27: 82-8. Available from: https://doi. org/10.1016/j.colegn.2019.03.004

19 Bossen C, Jensen LG, Udsen FW. Evaluation of a comprehensive EHR based on the DeLone and McLean model for IS success: approach, results, and success factors. Int J Med Inform. 2013; 82(10): 940-53. Available from: https://doi.org/10.1016/j. ijmedinf.2013.05.010.

20 Nykanen P, Kaipio J, Kuusisto A. Evaluation of the national nursing model and four nursing documentation systems in Finland - Lessons learned and directions for the future. Int $J$ Med Inform. 2012; 81(8): 507-20. Available from: https://doi. org/10.1016/i.ijmedinf.2012.02.003.

21 Rathert C, Williams ES, Lawrence ER, Halbesleben JRB. Emotional exhaustion and workarounds in acute care: cross sectional tests of a theoretical framework. Int J Nurs Stud. 2012; 49(8): 969-77. Available from: https://doi.org/10.1016/j. ijnurstu.2012.02.011.

22 Paans W, Sermeus W, Nieweg RM, Van der Schans CP. D-Catch instrument: development and psychometric testing of a measurement instrument for nursing documentation in hospitals. J Adv Nurs. 2010; 66(6):1388-1400. Available from: https://doi.org/10.1111/j.1365-2648.2010.05302.x.

23 Botti M, Redley B, Nguyen L, Coleman K, Wickramasinghe N. Optimizing safety, fidelity and usability of an intelligent clinical support tool (ICST) for acute hospital care: an Australian case study using a multi-method Delphi process. Stud Health Technol Inform. 2015; 216: 912. Available from: https:// europepmc.org/article/med/26262214

24 Deloitte Access Economics. Economic benefits of SmartWard. 2014. Canberra: Deloitte. [cited 2021 Jan 20] Available from https://www2.deloitte.com/au/en/pages/economics/articles/ economic-benefits-smartward.html

25 Kent B. SmartWard development: evaluation of technology within simulated nursing settings. Melbourne: Deakin University. 2012.

24. Kent B, Redley B, Wickramasinghe N, Nguyen L, Taylor NJ, Moghimi $\mathrm{H}$, et al. Exploring nurses' reactions to a novel technology to support acute health care delivery. J Clin Nurs. 2015; 24(15-16): 2340-51. Available from: https://doi. org/10.1111/jocn.12881

25 Bail K, Davey R, Currie M, Gibson J, Merrick E, Redley B. Implementation pilot of a novel electronic bedside nursing chart: a mixed-method case study. Aust Health Rev. 2020; 44: 672-76. Available from: https://doi.org/10.1071/AH18231.

26 Mueller-Staub M, Lunney M, Odenbreit M, Needham I, Lavin MA, Van Achterberg T. Development of an instrument to measure the quality of documented nursing diagnoses, interventions and outcomes: the Q-DIO. J Clin Nurs. 2009; 18(7): 1027-37. Available from: https://doi.org/10.1111/j.13652702.2008.02603.x.
27 Mueller-Staub M. Preparing nurses to use standardized nursing language in the electronic health record. Stud Health Technol Inform. 2009; 146: 337-41. Available from: https://doi. org/10.3233/978-1-60750-024-7-337.

28 Mueller-Staub M, Lunney M, Lavin MA, Needham I, Odenbreit $M$, Van Achterberg T. Psychometric properties of Q-DIO, an instrument to measure the quality of documented nursing diagnoses, interventions and outcomes. Pflege. 2010; 23(2): 119-28. Available from: https://doi.org/10.1024/1012-5302/ a000024

29 Wang N, Bjorvell C, Hailey D, Yu P. Development of the quality of Australian Nursing Documentation in Aged Care (QANDAC) instrument to assess paper-based and electronic resident records. Australas J Ageing. 2014; 33(4): E18-E24. Available from: https://doi.org/10.1111/ajag.12072.

30 Redley B, Baker T. Have you SCAND MMe Please? A framework to prevent harm during acute hospitalisation of older persons: a retrospective audit. J Clin Nurs. 2018; 28(3-4): 560-74. Available from: https://doi.org/10.1111/jocn.14650.

31 Broderick MC, Coffey A. Person-centred care in nursing documentation. Int J Older People Nurs. 2013; 8(4): 309-18. Available from: https://doi.org/10.1111/opn.12012.

32 Jedwab RM, Chalmers C, Dobroff N, Redley B. Measuring nursing benefits of an electronic medical record system: a scoping review. Collegian. 2019; 26(5): 562-82. Available from: https://doi.org/10.1016/j.colegn.2019.01.003.

33 Redley B, Raggatt M. Use of standard risk screening and assessment forms to prevent harm to older people in Australian hospitals: a mixed methods study. BMJ Qual Saf. 2017; 26(9): 704-13. Available from: https://doi.org/10.1136/ bmjas-2016-005867.

34 Vaughn VM, Linder JA. Thoughtless design of the electronic health record drives overuse, but purposeful design can nudge improved patient care. BMJ Qual Saf. 2018; 27(8): 583-86. Available from: https://doi.org/10.1136/bmjqs-2017-007578.

35 Michie S. Behaviour change beyond nudge. London University College: London. 2015

36 Patel MS, Volpp KG, Asch DA. Nudge units to improve the delivery of health care. N Engl J Med. 2018; 378(3): 214. Available from: https://doi.org/10.1056/NEJMp1712984.

37 Mlakar T, Mihelic Zajec A, Jevsnik M. Use of a nudge tool for improving hand hygiene in a nursing team in home for elderly people - case study. Int J Sanitary Engineering Res. 2017; 11(1): 33-46. Available from: https://repozitorij.uni-lj.si/Dokument. php?id=124923\&lang $=$ slv

38 Ostrovsky Y, Buttaro TM, Diamond J, Hayes JJI. Technology and dynamic pathways: how to improve nursing care, documentation, and efficiency. Iproceedings. 2016; 2(1): e31. Available from: https://doi.org/10.2196/iproc.6158.

39 Halpern SD. Using default options and other nudges to improve critical care. Crit Care Med. 2018; 46(3): 460-64. Available from: https://doi.org/10.1097/CCM.0000000000002898.

40 Karkkainen O, Bondas T, Eriksson K. Documentation of individualized patient care: a qualitative metasynthesis Nurs Ethics. 2005; 12(2): 123-32. Available from: https://doi. org/10.1191/0969733005ne769oa. 